\title{
Private Premium of Endowment Last Survivor and Joint Life Insurance with Pareto Distribution
}

\author{
Hasriati, Tumpal Parulian Nababan \\ Department of Mathematics, Faculty of Mathematics and Natural Sciences, University of Riau, Pekanbaru, Indonesia \\ Email address: \\ hasriati.hasri@gmail.com (Hasriati),tumpalpnababan@gmail.com (T. P. Nababan) \\ To cite this article: \\ Hasriati, Tumpal Parulian Nababan. Private Premium of Endowment Last Survivor and Joint Life Insurance with Pareto Distribution. \\ International Journal of Statistical Distributions and Applications. Vol. 5, No. 4, 2019, pp. 76-81. doi: 10.11648/j.ijsd.20190504.11
}

Received: October 7, 2019; Accepted: November 4, 2019; Published: November 8, 2019

\begin{abstract}
This paper studies a dual life insurance premium is determined with the combined status of last survivor and joint life involving two insurance participants who have a kinship relationship such as husband and wife, brother and sister, which they work in the same agency. In determining the policy to be made by the life insurance does not require two policies to be made, but enough to have only one policy. So that by having one policy expected premiums paid by life insurance participants to life insurance companies will be smaller than if you have to pay in two policies. Determination of insurance premiums dual life to be paid by an insurance party participant based on the chance of death from both life insurance participants, stating a condition that will continue as long as there is at least one member who is still alive and will cease after the death of the last person of its member, and also is an ongoing condition se long time all members of a combination of several people can survive and will stop after one of its members first dies, to determine the single premium and annual premium using the cash value of the initial life annuity from dual life insurance. Whereas the initial annuity cash value is influenced by the interest rate and discount factor and is also influenced by the combined life opportunity of the two insurance participants. Furthermore, from the chance of life will be obtained the chance of dying In formulating the chance of dying the insurance participant is used the Pareto distribution and to obtain the parameter values in the Pareto distribution the maximum Likelihood method is used. In order to obtain the chance of death and can be used to calculate a single premium and annual premium.
\end{abstract}

Keywords: Premi, Last Survivor, Joint Life, Distribusi Pareto, Maksimum Likelihood

\section{Introduction}

Old age causes inability to earn income and results in economic difficulties for workers themselves and their families. One effort to anticipate old age risk is to include every employee in a life insurance program. Life insurance is an insurance that provides payment of a certain amount of money for the death of the insured to the heirs or people who are entitled to receive it in accordance with the provisions and agreements made by the insured in a life insurance policy. Husband and wife who work in the same agency allows to take one insurance program with the same policy to facilitate payment.

Life insurance based on the amount of the insured is divided into two types, namely single (individual) life insurance and combined life insurance. In this combined life insurance there are one or more insurance participants such as husband and wife. In this article is joint insurance is discussed. According to Bowers et al. [2, 3, 4] combined life insurance $[5,7,8,10]$ can be divided into two, namely last survivor life insurance and joint life life insurance. Last survivor life insurance is a condition that will continue as long as there is at least one member who is still alive and will stop after the death of the last person of its members (all members died), while joint life life insurance is a condition that lasts for all members of the combined number of people can survive and will stop after one of their first members dies.

Based on the coverage period is divided into pure dual purpose life insurance, life insurance for life, term life insurance and dual life insurance. According to Futami [5] dual-purpose life insurance is a type of insurance which is a combination of pure dual-purpose life insurance and term life insurance which means that both within and at the end of the insurance period for policyholders, both death and survival will be paid for the sum insured.

In the discussion of joint insurance used for two 
participants, husband and wife insurance is the last survivor dual life survivor insurance and joint life. Futami [6] states that the last survivor dual purpose insurance is that if the insurance participant, i.e. husband and wife at the time of their last death or at the end of the period of coverage is still alive then the sum insured will be paid, while joint life's dual purpose insurance states that the sum insured will be paid if one of the husbands and the wife dies first. At the last survivors' life insurance and joint life is determined annual premium and single premium, where the annual premium is a series of payments made by insurance participants to the insurance company once a year within the time limit throughout the agreed insurance contract and a single premium is an insurance premium payment made by a participant only once during the agreed contract period when entering into an insurance participant. Premium payment is influenced by discount factors, the value of life annuities, life chances and chances of death. In determining the chances of life and the chance of dying for last-life survivor and joint life life insurance are used the Pareto distribution [13] of an Italian economist named Vilfredo Pareto (1848-1923).

\section{Annuity Joint Life and Last Survivor}

Determining the annual premium and single premium is influenced by the value of life opportunities and the chance of death. In actuarial science the survival function denoted by $S(x)$ is used to express the life opportunity denoted by ${ }_{t} p_{x}$ and the distribution function is denoted as $F(x)$ which is used to express the chance of death denoted by ${ }_{t} q_{x}[1,14$, $15]$.

The last survivor insurance life opportunity [16] is denoted by ${ }_{t} p_{\overline{x y}}$ and for the chance of dying the last survivor insurance is denoted by ${ }_{t} q_{\overline{x y}}$. To state the chance of dying last survivor insurance with two age insurance participants, namely age $x$ years and $y$ years stated with

$$
\begin{aligned}
& { }_{t} q_{\overline{x y}}={ }_{t} q_{x t} q_{y}, \\
& { }_{t} q_{\overline{x y}}=\left(1-{ }_{t} p_{x}\right)\left(1-{ }_{t} p_{y}\right),
\end{aligned}
$$

and for the chance of dying last survivor insurance can also be stated with

$$
{ }_{t} q_{\overline{x y}}=1-{ }_{t} p_{\overline{x y}} .
$$

From equation (2) the last survivor insurance life opportunity is stated as follows:

$$
{ }_{t} p_{x y}=1-{ }_{t} q_{x y}
$$

By substituting equation (1) into equation (3) the chances of last survivor insurance life can be stated as follows:

$$
{ }_{t} p_{x y}={ }_{t} p_{x}+{ }_{t} p_{y}-{ }_{t} p_{x y} .
$$

The chance of dying is delayed for last survivor insurance which states the chance of one between the age of $x$ years and $y$ years who will live up to $t$ years and is notated with ${ }_{t \mid u} q_{\overline{x y}}$. The chance of dying is delayed for the last survivor insurance stated with

$$
{ }_{t} q_{\overline{x y}}={ }_{t}\left|q_{x}+{ }_{t}\right| q_{y}-{ }_{t} \mid q_{x y},
$$

where the values of ${ }_{t} q_{x}$ and ${ }_{t} q_{y}$ from equation (3) is expressed with

$$
{ }_{t} q_{x}={ }_{t} p_{x}-{ }_{t+1} p_{x}
$$

and the value of ${ }_{t} q_{x y}$ of equation (4) is stated by

$$
{ }_{t} q_{x y}={ }_{t} p_{x y}-{ }_{t+u} p_{x y}
$$

with a value of $u=1$ year.

The life opportunity of a joint life who can survive up to $t+u$ years is expressed as

$$
\begin{aligned}
& { }_{t+u} p_{x y}={ }_{t} p_{x y u} p_{x+t ; y+t}, \\
& { }_{t+u} p_{x}={ }_{t} p_{x y}\left(1-{ }_{u} q_{x+t ; y+t}\right) .
\end{aligned}
$$

Finan $[4,11]$ states that on joint status there is also the chance of death pending insurance participants who are $x$ years and $y$ years will live up to $t$ years, then die in the following year $u$ stated as follows:

$$
{ }_{t \mid u} p_{x y}={ }_{t} p_{x y}-{ }_{t+u} p_{x y}
$$

Furthermore, by substituting Equation (7) into Equation (8), the probability of death of delayed joint life is obtained as follows:

$$
{ }_{t \mid u} q_{x y}={ }_{t} p_{x y}\left({ }_{u} q_{x+t ; y+t}\right)
$$

with the value $u=1$ the chance of delayed death for a joint status stating the probability of one between age $x$ years and $y$ years who will live up to $t$ years and is notated with ${ }_{t} q_{x y}$, so the chance of death in a combined delayed is expressed as

$$
{ }_{t} q_{x y}={ }_{t} p_{x y}\left(q_{x+t ; y+t}\right) .
$$

According to Futami [5] the payment of the last survivor's dual annuity cash value for 1 unit of payment is stated as follows:

$$
\ddot{a}_{\overline{x y}: \bar{n}}=\sum_{t=0}^{n-1} v_{t}^{t} p_{\overline{x y}}
$$

where $v$ expresses a discount factor, Kellison [9] and [11]states the discount factor for the coming $t$ years is

$$
v^{t}=\frac{1}{(1+i)^{t}}
$$




\section{Endowment Life Insurance Premiums Last Survivor and Joint Life}

Single premium of endowmentlast survivor life insurance where the period of coverage for $n$ years and the sum insured of 1 unit of payment is stated by

$$
A_{x y: n]}=R \sum_{t=0}^{n-1} v^{t+t}{ }_{t} q_{x y}+R v_{n}^{n} p_{\overline{x y}},
$$

The annual premium of Endowmentlast survivor life insurance is stated as follows:

$$
P_{\overline{x y: n]}}=\frac{A_{x y: \bar{n}} \bar{y}}{a_{\overline{x y} \bar{n}]}}
$$

Single premium of dual life joint life insurance with a coverage period of $n$ years and a sum insured of 1 unit of payment is stated by

$$
A_{x \hat{y}: n]}=R \sum_{t=0}^{n-1} v^{t+t}{ }_{t} \mid q_{x y}+R v^{n}{ }_{n} p_{x y}
$$

then the discount factor for the next $t+1$ year is

$$
v^{t+1}=\frac{1}{(1+i)^{t+1}}
$$

the annual premium of dual life joint life insurance using the Pareto distribution denoted $P_{x y: \bar{n} \mid}$ is stated as follows

$$
P_{x y: n]}=\frac{A_{x y: \bar{n}]}}{\bar{a}_{x y: n]}}
$$

\section{Annual Premium Using the Pareto Distribution}

Furthermore, determining the single and annual premiums is used the Pareto density function, namely

$$
f(x ; a, \theta)=\frac{a \theta^{a}}{x^{a+1}}, x>\theta, a>0, \theta>0
$$

In the Pareto distribution there is a parameter value $\theta$ and to determine the parameters of a Pareto distribution can be done with the maximum likelihood method. The maximum likelihood method is a parameter estimator method by maximizing the likelihood function, with

$$
F(x)=\int_{p}^{x} f(t) d t
$$

$$
\begin{aligned}
& =\int_{p}^{x} \frac{\theta p^{\theta}}{t^{\theta+1}} \\
& =\left(\theta p^{\theta}\right) \int_{p}^{x} t^{-(\theta+1)} d t \\
& =\left(\theta p^{\theta}\right)\left[-\frac{1}{\theta} t^{-\theta}\right]^{x} \\
& =\left(\theta p^{\theta}\right)\left[\left(-\frac{1}{\theta} x^{-\theta}\right)-\left(-\frac{1}{\theta} p^{-\theta}\right)\right] \\
& \left.\left.=\left(\frac{p}{p}\right)^{\theta}-\left(\frac{p}{x}\right)^{\theta}\right)\right] \\
& F(x)=1-\left(\frac{p}{x}\right)^{\theta}
\end{aligned}
$$

So the survival function is obtained as follows:

$$
S(x)=1-\left(\frac{p}{x}\right)^{\theta}
$$

Next estimate the Pareto distribution parameter values, as follows:

$$
\begin{gathered}
L(x ; p, \theta)=\prod_{i=1}^{n}\left(\frac{\theta p^{\theta}}{x^{\theta+1}}\right), \\
=\frac{\prod_{i=1}^{n} \theta p^{\theta}}{\prod_{i=1}^{n} x^{\theta+1}}
\end{gathered}
$$

$$
L(x ; p, \theta)=\frac{\theta^{n} p^{\theta n}}{\prod_{i=1}^{n}\left(x^{\theta+1}\right)}
$$

$$
\begin{gathered}
\ln L(x ; p, \theta)=\ln \left[\frac{\theta^{n} p^{\theta n}}{\prod_{i=1}^{n}\left(x^{\theta+1}\right)}\right], \\
=\ln \left(\theta^{n}\right)+\ln \left(p^{\theta n}\right)-\ln \left(\prod_{i=1}^{n}\left(x^{\theta+1}\right)\right), \\
=\ln L(x ; p, \theta)+n \ln (p)-(\theta+1) \sum_{i=1}^{n} \ln \left(x_{i}\right)
\end{gathered}
$$

To get the parameter $\theta$ estimation is done by finding the derivative in equation (12) of $\theta$ as follows:

$$
\begin{aligned}
& \frac{\partial}{\partial \theta}(\ln L(x ; p ; \theta))=\frac{\partial}{\partial \theta}\left(n \ln (\theta)+n \ln (p)-(\theta+1) \sum_{i=1}^{n} \ln \left(x_{i}\right)\right) \\
& =\frac{\partial}{\partial \theta}(n \ln (\theta))+\frac{\partial}{\partial \theta}\left(n \theta \ln (p)-\frac{\partial}{\partial \theta}(\theta+1) \sum_{i=1}^{n} \ln \left(x_{i}\right)\right)
\end{aligned}
$$




$$
\frac{\partial}{\partial \theta}(\ln L(x ; p ; \theta))=\frac{n}{\theta} n \ln (p)-\sum_{i=1}^{n} \ln \left(x_{i}\right)
$$

so that we have

$$
\hat{\theta}=\frac{n}{\sum_{i=1}^{n} \ln \left(x_{i}\right)-n \ln (p)}
$$

In the same way to estimate the value of the Pareto distribution parameter to get the parameter $\theta$ for $y$ years old obtained as follows:

$$
\hat{\boldsymbol{\theta}}=\frac{n}{\sum_{i=1}^{n} \ln \left(y_{i}\right)-n \ln (p)}
$$

Furthermore, the chances of survival with the Pareto distribution are as follows:

$$
\begin{gathered}
F_{T(x)}(t)=\frac{F(x+t)-F(x)}{S(x)} \\
=\frac{\left[1-\left(\frac{p}{x+t}\right)^{\theta}\right]-\left[1-\left(\frac{p}{x}\right)^{\theta}\right]}{\left(\frac{p}{x}\right)^{\theta}} \\
=\frac{\left(\frac{p}{x}\right)^{\theta}-\left(\frac{p}{x+t}\right)^{\theta}}{\left(\frac{p}{x}\right)^{\theta}} \\
F_{T(x)}(t)=1-\left(\frac{x}{x+t}\right)^{\theta}
\end{gathered}
$$

The function $F_{T(x)}(t)$ represents the chance that someone who is $x$ years old will die after being $x+t$ years expressed by

$$
{ }_{1} q_{x}=1-\left(\frac{x}{x+t}\right)^{\theta}
$$

Then the chance of life for someone aged $x$ years to the next $t$ years using the Pareto distribution is obtained,

$$
\begin{gathered}
{ }_{t} p_{x}=\left(\frac{x}{x+t}\right)^{\theta} . \\
A_{x y \cdot \bar{n} \mid}=R \sum_{t=0}^{n-1}\left(\begin{array}{l}
\left.\left(\frac{1}{(1+i)^{t+1}}\right)\left(\left(\frac{x}{x+t}\right)^{\theta}-\left(\frac{x}{x+t+1}\right)^{\theta}\right)+\left(\left(\frac{y}{y+t}\right)^{\theta}-\left(\frac{y}{y+t+1}\right)^{\theta}\right)\right)+R\left(v^{n} \cdot{ }_{n} p_{\overline{x y}}\right), \\
-\left(\left(\frac{x}{x+t}\right)^{\theta}-\left(\frac{x}{x+t+1}\right)^{\theta}\right)\left(\left(\frac{y}{y+t}\right)^{\theta}-\left(\frac{y}{y+t+1}\right)^{\theta}\right)
\end{array}\right.
\end{gathered}
$$

Whereas the life chances of someone who is $y$ years old to the next $t$ using the Pareto distribution is stated by

$$
{ }_{t} p_{y}=\left(\frac{y}{y+t}\right)^{\theta} \text {. }
$$

The combined life opportunities of $x$ and $y$ years to the next $t$ using the Pareto distribution are expressed as

$$
{ }_{t} p_{x y}=\left(\frac{x}{x+t}\right)^{\theta} \cdot\left(\frac{y}{y+t}\right)^{\theta} .
$$

Furthermore, for the last survivor life chances of insurance using the Pareto distribution by substituting equation (14), equation (15) and equation (16) into equation (4) is obtained as follows:

$$
{ }_{t} p_{x y}=\left(\frac{x}{x+t}\right)^{\theta}+\left(\frac{y}{y+t}\right)^{\theta}-\left(\left(\frac{x}{x+t}\right)^{\theta} \cdot\left(\frac{y}{y+t}\right)\right)^{\theta},
$$

and for the chance of dying the last survivor insurance using the Pareto distribution is obtained by substituting equation (17) into equation (3) as follows:

$$
{ }_{t} q_{\overline{x y}}=1-\left(\left(\frac{x}{x+t}\right)^{\theta}+\left(\frac{y}{y+t}\right)^{\theta}-\left(\left(\frac{x}{x+t}\right)^{\theta} \cdot\left(\frac{y}{y+t}\right)\right)^{\theta}\right) .
$$

The chance of dying delayed for the last survivor insurance is obtained as

$$
\begin{aligned}
{ }_{t} q_{\overline{x y}}= & \left(\left(\frac{x}{x+t}\right)^{\theta}-\left(\frac{x}{x+t+1}\right)^{\theta}\right)+\left(\left(\frac{y}{y+t}\right)^{\theta}-\left(\frac{y}{y+t+1}\right)^{\theta}\right) \\
& -\left(\left(\frac{x}{x+t}\right)^{\theta}-\left(\frac{x}{x+t+1}\right)^{\theta}\right)\left(\left(\frac{y}{y+t}\right)^{\theta}-\left(\frac{y}{y+t+1}\right)^{\theta}\right),
\end{aligned}
$$

The value of the last survivor dual life insurance annuity using the Pareto distribution is

$$
\ddot{a}_{x y \cdot \bar{n}]}=\sum_{t=0}^{n-1}\left(\left(\frac{1}{(1+i)^{t}}\right)\left(\frac{x}{x+t}\right)^{\theta}+\left(\frac{y}{y+t}\right)^{\theta}-\left(\left(\frac{x}{x+t}\right)^{\theta} \cdot\left(\frac{x}{y+t}\right)^{\theta}\right)\right) \text {. }
$$

So that the single premium of endowment last survivor life insurance using the Pareto distribution is obtained as follows: 
The annual premium of endowment last survivor life insurance is

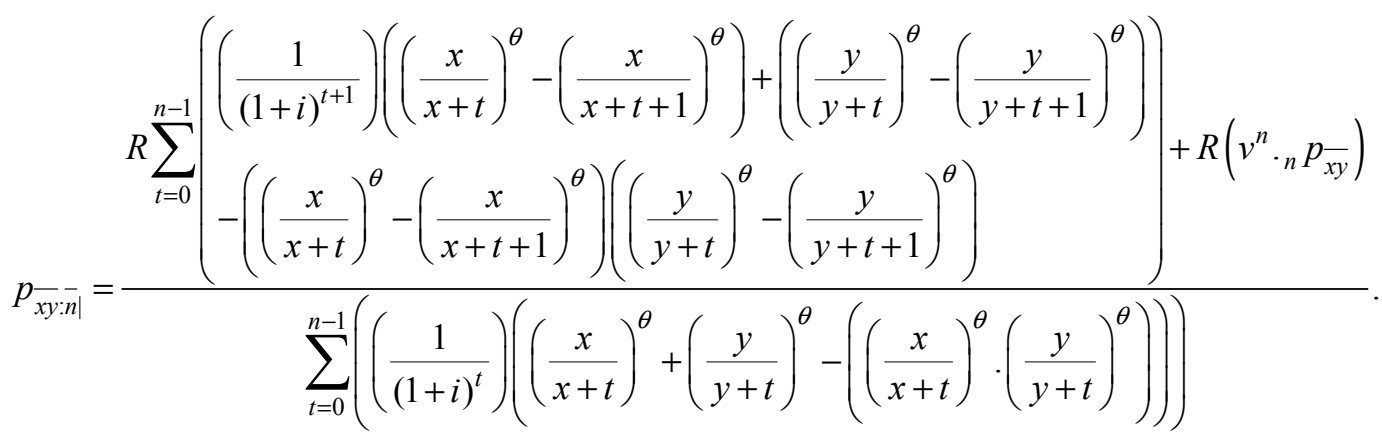

For endowment joint life insurance, the chance of a delayed joint is

$$
{ }_{t} q_{x y}=\left(\frac{x}{x+t}\right)^{\theta}\left(\frac{y}{y+t}\right)^{\theta}-\left(\frac{x}{x+t+1}\right)^{\theta}\left(\frac{y}{y+t+1}\right)^{\theta}
$$

The value of a dual life joint life insurance annuity using the Pareto distribution is

$$
\ddot{a}_{x y: n}=\sum_{t=0}^{n-1} v^{t}\left(\left(\frac{x}{x+t}\right)^{\theta}\left(\frac{y}{y+t}\right)^{\theta}\right)
$$

The single premium for endowment joint life insurance using the Pareto distribution is,

$$
A_{x \hat{y}: n]}=R \sum_{t=0}^{n-1} v^{t+t}\left(\left(\frac{x}{x+t}\right)^{\theta}\left(\frac{y}{y+t}\right)^{\theta}-\left(\frac{x}{x+t+1}\right)^{\theta}\left(\frac{y}{y+t+1}\right)^{\theta}\right)+R v_{n}^{n} p_{x y}
$$

The annual premium of endowment joint life life insurance is as follows:

$$
P_{x \hat{y}: n]}=\frac{R \sum_{t=0}^{n-1} v^{t+1}\left(\left(\frac{x}{x+t}\right)^{\theta}\left(\frac{y}{y+t}\right)^{\theta}-\left(\frac{x}{x+t+1}\right)^{\theta}\left(\frac{y}{y+t+1}\right)^{\theta}\right)+R v^{n}{ }_{n} p_{x y}}{\sum_{t=0}^{n-1} v^{t}\left(\left(\frac{x}{x+t}\right)^{\theta}\left(\frac{y}{y+t}\right)^{\theta}\right)}
$$

Example: A husband and wife who work in the same institution agree to take part in the last survivors' dual life insurance. When taking the insurance age of the husband is 35 years old and the wife is 32 years old and will take the insurance period for 20 years. The sum insured will be received in the amount of $\mathrm{Rp} 20,000,000.00$ which will later be paid to the heirs or participants. Mortality table used is to use TMI 1999 and use an interest rate of $15 \%$. In this paper, we will determine the amount of the annual premium for last-survivor life insurance using the Pareto distribution.

From the example above the case is known $x=35, y=30$, $n=10, R=\mathrm{Rp} 20,000,000.00, i=15 \%$. Furthermore, looking for life opportunities and the chance of dying delayed last survivor insurance from TMI 1999 and can be seen in Table 1.
Table 1. Life opportunities and chances of dying delayed by last survivor insurance.

\begin{tabular}{llllll}
\hline $\mathbf{t}$ & $\boldsymbol{t}_{\boldsymbol{x y}}$ & $\boldsymbol{t}^{\boldsymbol{q}} \overline{\boldsymbol{x y}}$ & $\mathbf{t}$ & ${ }_{\boldsymbol{t}} \boldsymbol{p}_{\boldsymbol{x y}}$ & ${ }_{\boldsymbol{t}} \boldsymbol{q}_{\boldsymbol{x y}}$ \\
\hline 0 & 1,000000 & 0,0032 & 10 & 0,995825 & 0,00073 \\
1 & 0,999944 & 0,000161 & 11 & 0,995095 & 0,000766 \\
2 & 0,999783 & 0,000254 & 12 & 0,994329 & 0,000798 \\
3 & 0,999529 & 0,000338 & 13 & 0,993531 & 0,000827 \\
4 & 0,999191 & 0,000413 & 14 & 0,992704 & 0,000854 \\
5 & 0,998778 & 0,000481 & 15 & 0,99185 & 0,000877 \\
6 & 0,998298 & 0,000541 & 16 & 0,990973 & 0,000898 \\
7 & 0,997756 & 0,000596 & 17 & 0,990075 & 0,000917 \\
8 & 0,99716 & 0,000645 & 18 & 0,989157 & 0,000934 \\
9 & 0,996514 & 0,00069 & 19 & 0,988223 & 0,000949 \\
\hline
\end{tabular}

Then the value of the discount factor are found by substituting the value of $i=15 \%$ into equation (9) and equation (11) as seen in Table 2. 
Table 2. Discount factor values.

\begin{tabular}{llllll}
\hline $\mathbf{t}$ & $\mathbf{v}^{\mathbf{t}}$ & $\mathbf{v}^{\mathbf{t + 1}}$ & $\mathbf{t}$ & $\mathbf{v}^{\mathbf{t}}$ & $\mathbf{v}^{\mathbf{t + 1}}$ \\
\hline 0 & 1,00000 & 0,869565 & 10 & 0,247185 & 0,214943 \\
1 & 0,869565 & 0,756144 & 11 & 0,214943 & 0,186907 \\
2 & 0,756144 & 0,657516 & 12 & 0,186907 & 0,162528 \\
3 & 0,657516 & 0,571753 & 13 & 0,162528 & 0,141329 \\
4 & 0,571753 & 0,497177 & 14 & 0,141329 & 0,122894 \\
5 & 0,497177 & 0,432328 & 15 & 0,122894 & 0,106865 \\
6 & 0,432328 & 0,375937 & 16 & 0,106865 & 0,092926 \\
7 & 0,375937 & 0,326902 & 17 & 0,092926 & 0,080805 \\
8 & 0,326902 & 0,284262 & 18 & 0,080805 & 0,070265 \\
9 & 0,284262 & 0,247185 & 19 & 0,070265 & 0,0611 \\
\hline
\end{tabular}

Next to find the value of $\hat{\theta}$ which is a parameter $\theta$ estimator usia for age $x$ years, the value of $\theta$ is obtained from equation (20)

$$
\begin{gathered}
\theta=\frac{20}{79,74662-20 \ln (1)} \\
\theta=0,250794
\end{gathered}
$$

and for the value of $\hat{\theta}$ which is the parameter $\theta$ estimate for $y$ years of age, the value of $\theta$ is obtained from equation (21)

$$
\begin{aligned}
& \theta=\frac{20}{78,26861-20 \ln (1)} \\
& \theta=0,255553
\end{aligned}
$$

After the $\theta$ value is obtained, then the annuity, single premium and annual premium values are used using the Pareto distribution by substituting the values in Table 1, Table 2, into equation (33), equation (34) and equation (35) presented in Table 3.

Table 3. Calculation of annuities and premiums $l$.

\begin{tabular}{lll}
\hline Annuity & Single premium & Annual premium \\
\hline $\mathrm{Rp} 7,183586$ & $\mathrm{Rp} 1.496 .191$ & $\mathrm{Rp} 208.279$ \\
\hline
\end{tabular}

\section{Conclusion}

The last survivor life insurance coverage is paid to the heirs until the last death of the insurance participant. The cash value of the annuity for life insurance for the last survivor is influenced by the discount factor and the chance of life of the insurance participant. By using the Pareto distribution a single premium is less than the annual premium. So for a husband and wife who work in the same agency would be better to use last survivor insurance.

\section{References}

[1] L. J. Bain dan M. Engelhardt. (1992). Introduction to Probability and Mathematical Statistics, Second Edition. Duxbury. Pacific Grove. California.

[2] N. Bowers, L. J. Gerber dan U. Hans. (1997). Actuarial Mathematics, Second Ed. The Society Of Actuaries. Schaunburg Illinois.

[3] D. C. M. Dickson, M. R. Hardy dan H. R. Waters. (2009) Actuarial Mathematics for Life Contingent Risk, Cambridge University Press, Cambridge.

[4] M. B. Finan, A Reading of Life Contingency Model: A Preparation for Exam $M L C / 3 L$, Arkansas Teach University, Arkansas, 2011.

[5] T. Futami. (1993). Matematika Asuransi Jiwa, Bagian I, Terj. Seimei Hoken Sugaku, Gekan (92 Revision), oleh G. Herliyanto. Oriental Life Insurane Cultural Development Center. Tokyo.

[6] T. Futami. (1994). Matematika Asuransi Jiwa, Bagian II, Terj. Seimei Hoken Sugaku, Gekan (92 Revision), oleh G. Herliyanto. Oriental Life Insurane Cultural Development Center. Tokyo.

[7] Heekyung Youn, Arkady Shemyakin, Edwin Herman, (2002). A Re-examination of Joint Mortality Functions, North Amirican Actuarial Journal Volume 6, Number 1, p. 166-170.

[8] A. Jhon dan L. Albert. (2016). "Actuarial Analysis of Single Life Status and Multiple Life Statuses". American Journal of Theoretical and Applied Statistics 2016; 5 (3); 123-131.

[9] S. G. Kellison. (1991). The Theory of Interest. Richard D. Irwin Inc, Homewood.

[10] A. Matvejevs dan A. Matvejevs, (2001) Insurance models for joint life and last survivor nenefits, Informatica, 12, 547-558.

[11] Robert Musian, (2003). Mathematics of Interest Rate, Insurance, Social Security, and Pensiuns Prentice-Hall, London.

[12] Roger J, Gray and Susan M. Pitts, (2012) Risk Modelling in General Insurance, International Series on Actuarial Science, Cambridge Universitas Press.

[13] M. Rytgaard. (1990). "Estimation in the Pareto distribution". Astin Bulletin 1990; 20; 202-216.

[14] R. E. Walpole. (2007). Probability and Statistics for Engineers and Scientists, Eighth Edition. Pearson Education Internasional. London.

[15] R. E. Walpole dan R. H. Myers. (2012). Probability and Statistics for Engineering and Scientist, Ninth Edition, Prentice-Hall, Boston.

[16] Youn, H and Shemyakin, A. (2001). Pricing Practices for Joint Last Survivor Insurance, Actuarial Research Clearing House. 